\title{
The Design of Beverage Vending Machines Based on PLC
}

\author{
Yadong $\mathrm{Niu}^{1, \mathrm{a}}$, Jian $\mathrm{Chu}^{2, \mathrm{~b}}$ \\ ${ }^{1}$ Dagu South Road No. 1310, Tianjin,China \\ ${ }^{2}$ Dagu South Road No. 1310, Tianjin,China \\ aemail:453109234@qq.com
}

\begin{abstract}
Keywords: PLC(Programmable Logic Controller);Beverage vending machine;Module Abstract. The vending machine is a kind of commercial automatic equipment that integrates light, machine and light. And it can finish to sell without vendors.Beverage vending machine can be 24 hours in the sale of beverage products without any limitation of place and time. Because it is very convenient and not only can save the time of customers, but also the vendors, thus it brings great convenience to the masses. This paper based on Siemens S7-300PLC and use modular to finish the design of beverage vending machines. And achieving four parts that they are coin realized modules, merchandise selection module, coins and merchandise display module.
\end{abstract}

\section{Introduction}

\section{The basis and significance of this topic}

With the development of the recent science and technology, the most obvious is that the function of the vending machine has got a further development. Nowadays, the vending machine is not only a kind of machine which its function only has sale goods, but also it is a kind of commercial automation equipment that integrates many the most advanced technology which includes light, machine and electricity. From here we can see that its function gets a lot of changes. Beverage vending machine can be 24 hours in the sale of beverage products without any limitation of place and time. It is very convenient and easy to operate and very popular among office workers. Many of the city's public places which are placed a vending machine. Different occasions cause that different goods for sale.

From the perspective of development trend. While the change of production patterns, consumption patterns and environment will cause new distribution channel. The financial, material resources and manpower demand continue to rise with the advent of department stores, supermarkets shopping malls and other new distribution channels. But considering other restriction factors like place and time limitations and shopping convenience. So the vending machine without human intervention emerged in the world. The vending machine can overcome the limitation of time, even though in the midnight it can also sale. This is the biggest advantage of the vending machine. Every coin has two sides, it also has some disadvantages, f or example, the volume is limited, if we want to expand the capacity of the vending machine, it will produce more cost.

\section{The present research situation and development trend at home and abroad}

In China,the vending machine will be a huge potential industry. After the department stores, the supermarkets, it will become the third revolution and its prospects are very broad. Selling the goods can be customized according to the display place, including hot and cold drinks, snacks, phone card and foreign imports of goods, etc. Through the system of the smart sales that inventory, logistics information and sale information can be accurate and timely feedback to customers and managers. In addition, it supports multiple payment transaction mode, and convenient to achieve large amount of payments and transactions. In 2004, through the mobile phones shopping began to appear in the domestic wireless vending machine, nankai Gede company where in Tianjin has developed this type of vending machines.

Development is relatively mature in foreign countries. Japan vending industry has more than 2000 kinds of models, more than 6000 kinds of commodities. Operators as many as 10800 in the United States. 


\section{Programmable Logic Controller(PLC)}

\section{The definition of PLC}

Programmable logic controller(PLC) is a kind of digital computing based on electronic operating system and mainly apply in industrial environment. It mainly adopts the programmable memory which is used in internal storage controller logic operation, sequence control, counting timing and arithmetic operations instruction, and through the digital or analog input and output to control various types of mechanical production process. It is the core part of industrial control.

\section{The introduction of PLC}

The core of the traditional control system of vending machine uses SCM (Single Chip Microcomputer). If use this kind of controller, a lot of work must to be done on the I/O interface, thus the anti-interference of the system is very poor. However, PLC is a new type of industrial control equipment. It integrates computer technology, automatic control and communication. Its characteristics are as follows:

1. Strong anti-interference ability, high reliability;

2. Complete perfect function, strong applicability;

3. Easy to use, welcomed by the engineering and technical personnel;

4. The design of the system, the construction of the workload is small, easy maintenance, easy to transform;

5. Small volume, light weigh, low energy consumption;

6. The logic control switch;

7. Analog control;

8. Data processing;

9. Communication and networking.

Therefore, PLC has been widely used in the field of industrial control.

\section{The composition of PLC}

PLC is made up of CPU, power supply, storage and input/output interface circuit, etc. General composition of PLC is designed as shown in Fig.1. Modular structure of PLC is usually composed of a unit module, the module has the CPU module, input/output module, power supply module, etc. They like blocks, inserting on the frame when you use them. Each module is separate, it can be flexibly configured according to the requirement of the designers.

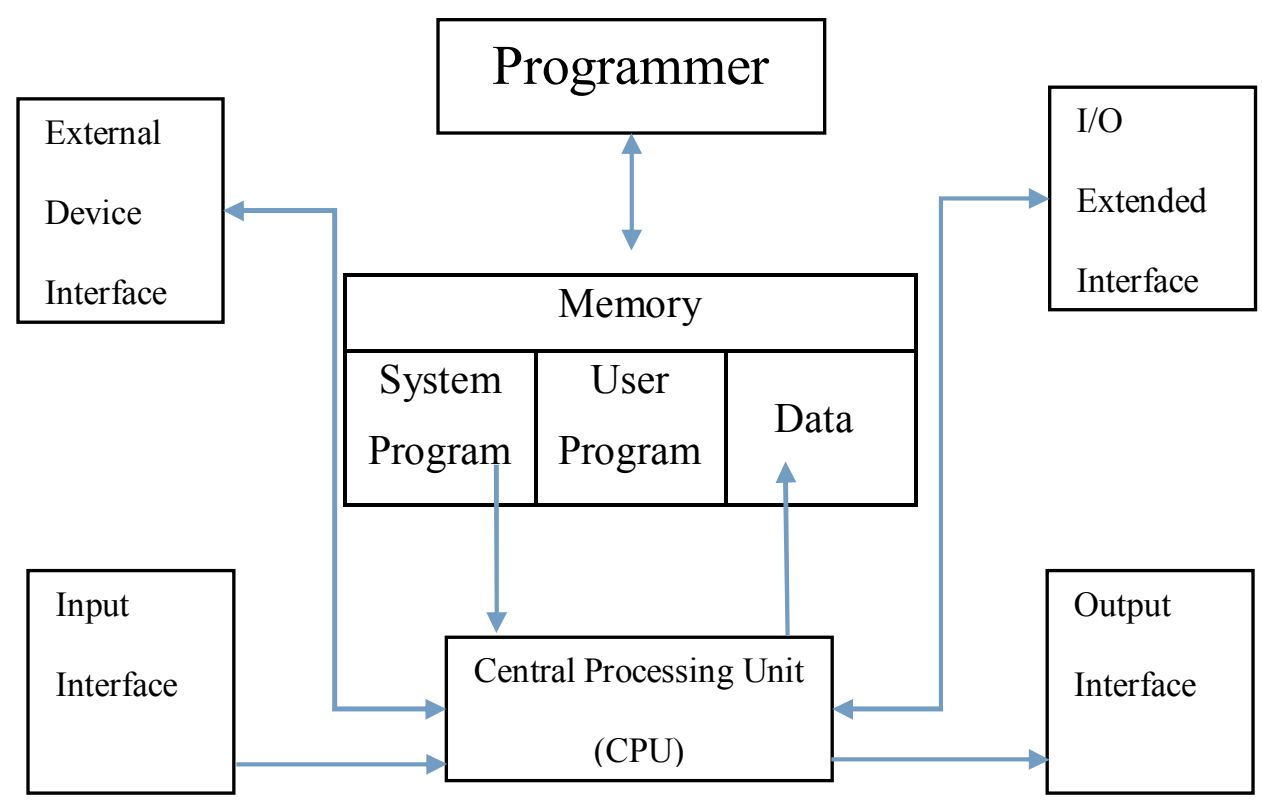

Fig.1 The composition of PLC

The working principle of PLC 
The working principle of PLC is cycle scanning work which focus on the input and output. When the PLC is powered on, the system will make an initialization for the PLC, and then scanned. Scanning the cycle of repeating, unless meets terminators, after this will return to the starting point. Each scan time is referred to as a scan cycle. There are three stages of the scanning process, respectively are input sampling stage, the program execution stage and output refresh stage. The three stages are the core of the working process of the PLC, which at the same time are the real essence of PLC. PLC scan process as shown in Fig.2.

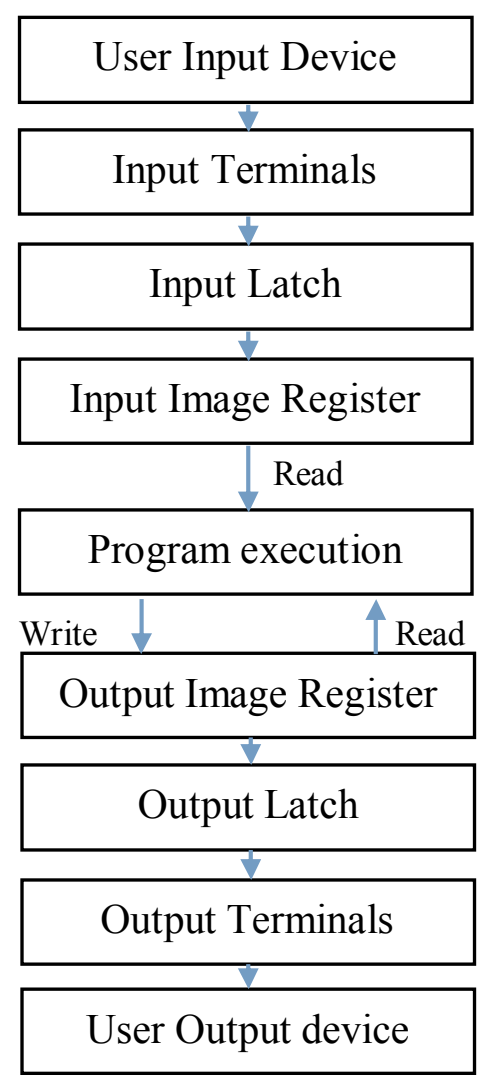

Fig.2 PLC scan process

\section{The introduction of beverage vending machine}

The main content of beverage vending machine design

If the customer within 2 minutes or within 20s after buying the stuff without any response, vending machine will be out of money. This paper assumes that it can identify three types of prices, respectively are $1 \mathrm{RMB}^{1 *}, 5 \mathrm{RMB}, 10 \mathrm{RMB}$, simulated by push button switch. The vending machine can provide two kinds of drinks $\mathrm{A}$ and $\mathrm{B}$. The price is $10 \mathrm{RMB}$ and $15 \mathrm{RMB}$ respectively. Customers put money greater than the purchase price, the corresponding drinks light will bright. And two different kinds of beverages use two different light instead. The work flow chart of the vending machine as shown in Fig.3. 


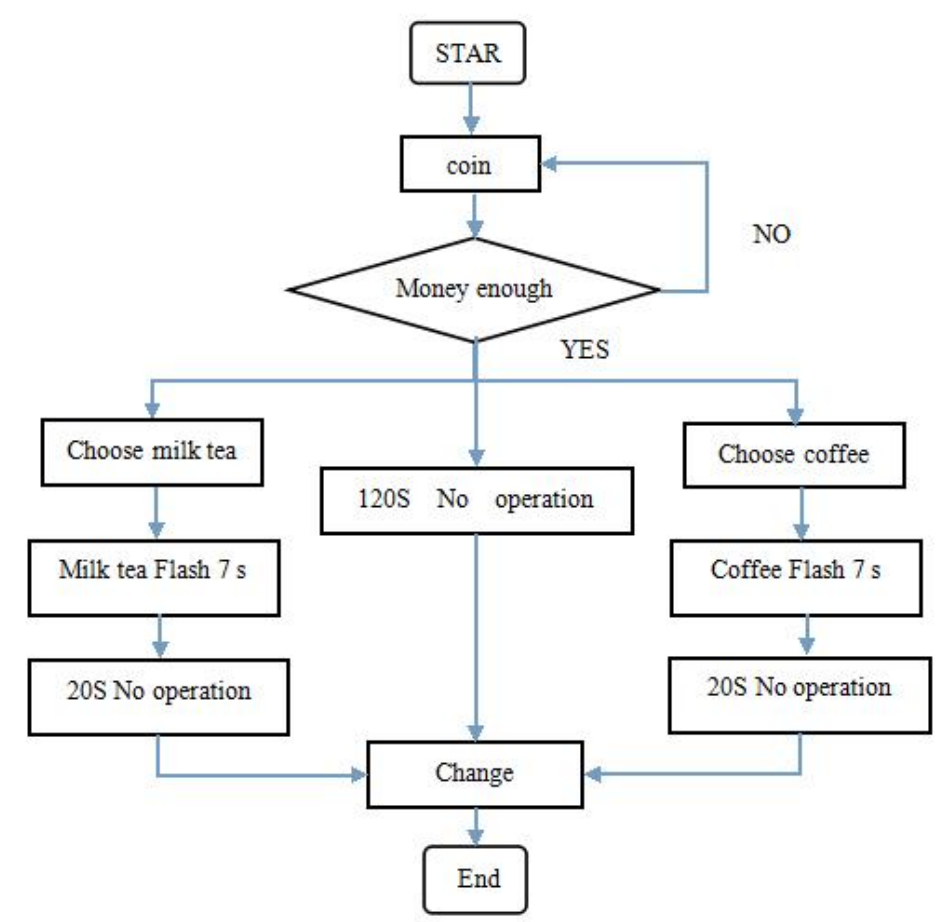

Fig.3 The work flow chart

\section{The basic ideas of the vending machine}

The main window of this paper is to use PLC and kingview control, through the PLC programming in the first, after programming and debugging, then using kingview to draw the vending machine style and some simple functions, such as beverage selection, work function, display, etc. To link of each pattern, finally through kingview detecting the working condition of the vending machine.

The vending machine module

Coin-operated module

The main function of the paper of the vending machine is that counts coins. Then to make the appropriate response according to the result of calculation. The customers want to buy what kind of drinks and according to the tips to make a choice. If the money which puts into the machine is more than the price of drinks can press the change button, the vending machine will give the rest of the money to customers after precise calculation.

Coins display module

When the customers put money into the machine, it will show the total number of coins. After the customers select goods, then correspondingly minus the price of goods. If customers want to buy others, continue to select goods. Otherwise, press the change button.

Commodity selection module

When the customers put money into the machine, if the value of money is great than the value of all the goods, then the indicator lights of all the goods will shine; if it is greater than the value of part of the goods, then only a portion indicator light of the goods will shine. The bright lights on or off is a good way to let the customers know what kind of products can be purchased and what kind of products can not be purchased.

Commodity discharging module

Selecting the goods what you want to buy and pay the amount. There will be a corresponding output signal to the switch and discharging goods. 


\section{The design of hardware}

\section{The choice of PLC}

We have several aspects to consider when we choose a CPU.

Size should be suitable;

Function is fairly, structure is reasonable;

The function of input/output, and the selection of load capacity.

Based on the above arguments, this paper uses Germany Siemens S7-200 series, CPU is 226, its $\mathrm{A} / \mathrm{D}, \mathrm{D} / \mathrm{A}$ conversion accuracy is more higher and faster.An analog module with $3 \mathrm{road} \mathrm{A} / \mathrm{D}, 1 \mathrm{road}$ $\mathrm{D} / \mathrm{A}$ and analog module is lower than others and high cost performance. CPU running speed and contain rich instructions.S7-200 has more input/output points. It contains four high speed counter, two high speed outlet, stronger communication network, equipped with two 232/485 communication port. Generally available in the demanding of small and medium-sized system. The complete physical S7-200 as shown in Fig.4

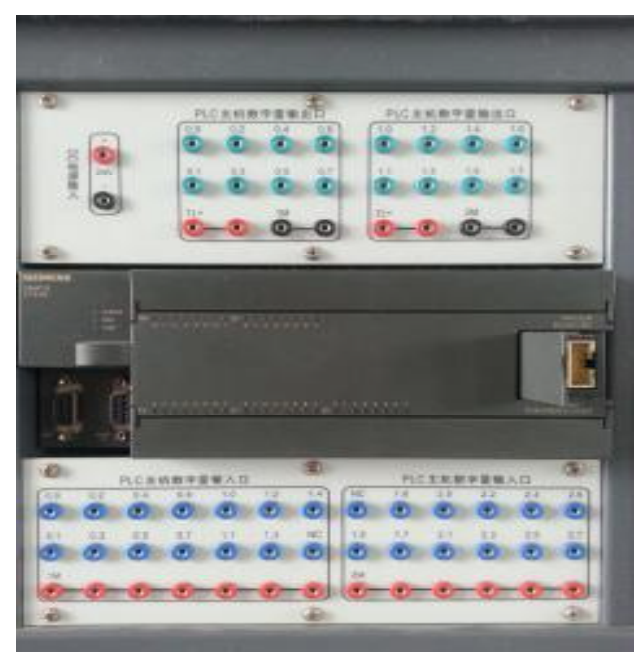

Fig.4 The complete physical S7-200

\section{The vending machine I/O point distribution}

Input/output unit is commonly called the $\mathrm{I} / \mathrm{O}$ element or the $\mathrm{I} / \mathrm{O}$ module, it mainly contains two parts: interface circuit that connects with a controlled equipment, input and output image register. Industrial production control is through the PLC input/output unit to control. PLC receives a variety of signal through the input interface. Then converts these signals into CPU what can be identified and dealt with through the external interface circuit. And the signal will be put into the input image register. At the same time, in order to control the controlled object, PLC converts the weak control signal into the strong electric signal what the scene need and output the signal through the output interface circuit.

\section{The design of software}

\section{The introduction of SETP7 Micro/WIN}

SETP7-Micro/WIN is a windows application, and it is designed by German Siemens company, its function is quite strong, users can be programmed according to different requirements. It can be able to connect configuration for real-time monitoring. Its birth solves a lot of questions for industrial automation and are very popular all over the world. 


\section{The design of program}

Arithmetic instruction

We should pay attention to the allocation of storage units. IN1, IN2 and OUT can use different storage unit in the use of LAD programming. This procedure is relatively clear. But in the use of STL programming, OUT and other operations use the same memory units. It may be a little inconvenient. The function of logic operation is to deal with logic number. According to the different nature of the logic operation that can be divided into logic or, logic and,xor and counter,etc.

Timer

The timer is one of the most commonly used components in PLC. When programming, the timer can be as the timer and also can be as a pulse. In the program firstly is to set the value of the timer. In the operation, if the input conditions are met, the timer begins to timing. And timer will act when the timer reaches the set value.

Counter

The counter is used to cumulative number of input pulse. In the practical application is mainly used to count the number of products or perform complex logic control task. The use of counter is similar to the use of timer. In programming input a value and it will act when the counter reaches the set value.

Compare instruction

Compare instruction is that comparing two numerical values or string in the specified conditions. When conditions are established, the contact will close. However, compare instruction is often referred to bit instruction. In the practical application it provides a lot of convenient for the lower limitation and the higher limitation of control and numerical condition judgment.

\section{Conclusion}

Automatic beverage vending machine controller is designed to use the PLC controller. If you want to increase the variety and quantity of goods. You only need to increase the corresponding port number of the input and output. The original hardware connection does not change. As for the software design, you can make the appropriate changes according to different control requirements. Because it has strong ability to adapt to the different conditions. This is one of the important reasons for PLC control system can be widely used in automatic beverage vending machine.

\section{References}

[1] Probart, C, McDonnell, E, Bailey-Davis, Letal. Existence and predictors of soft drink advertisements in Pennsylvania high schools. Journal of the American Dietetic Association, 2006.

[2] Siemens S7-200 Programmable Controller System Manual. Siemens Ltd., 1999.

[3] Jun Ma. A beverage with PLC control of automatic vending machine[J]. Professional, 2012.

[4] Changchu Liao.PLC programming and applications[M]. Beijing: Mechanical industry press, 2007. 